\title{
RTG Den Haag 9 januari 2018 (schending beroepsgeheim), m.nt. prof. mr. M.R. Bruning en mr. drs. M.P. Sombroek
}

Regionaal Tuchtcollege voor de Gezondheidszorg Den Haag 9 januari 2018 (mr. A.E.B. ter Heide, voorzitter, mr. H.M. Wattendorff, lid-jurist, R.P. van Straaten, dr. B. van Ek, H.N. Koetsier, leden-artsen), zaaknr. 2017-170, ECLI:NL:TGZRSGR:2018:12, Ouders van E tegen huisarts $A$

\section{Het verloop van de procedure}

1.1 Het verloop van de procedure blijkt uit:

- het klaagschrift met bijlagen, ontvangen op 15 juni 2017

- het verweerschrift met bijlagen

- de brief d.d. 13 oktober 2017 van mr. De Groot met productie 2 .

1.2 De partijen hebben afgezien van de mogelijkheid om in het vooronderzoek mondeling te worden gehoord.

1.3 De mondelinge behandeling door het College heeft plaatsgevonden ter openbare terechtzitting van 14 november 2017. De partijen, verweerder bijgestaan door zijn gemachtigde, zijn verschenen en hebben hun standpunten mondeling toegelicht.

\section{De feiten}

2.1 Klagers zijn de biologische ouders van E, geboren op 14 april 2005. E woont bij de moeder en de moeder heeft het gezag over E. De vader komt dagelijks bij de moeder en E over de vloer.

2.2 Verweerder is sinds 2013 huisarts en was enkele jaren de huisarts van de vader en van E. Als E een consult had bij verweerder, werd zij meestal begeleid door de vader. Sinds medio 2016 is de vader uitgeschreven uit de praktijk van verweerder. $\mathrm{E}$ is sinds februari 2017 uitgeschreven. De moeder had en heeft een andere huisarts.

2.3 In oktober/november 2015 heeft een medewerker van Jeugdbescherming West zich tot verweerder gewend met de vraag of verweerder signalen of zorgen had omtrent $\mathrm{E}$ in de sfeer van kindermishandeling. Verweerder heeft daarop geantwoord dat hij geen zorgen had op dat vlak, ook niet over de vader. 2.4 In 2016 is een voorlopige ondertoezichtstelling (OTS) afgegeven voor $\mathrm{E}$ in verband met een vermoeden van kindermishandeling. Er liep een onderzoek van de Raad voor de Kinderbescherming (hierna ook: RvdK).

2.5 Op 29 maart 2016 is de moeder bij verweerder op het spreekuur gekomen en heeft zij een gesprek met verweerder gehad. De door verweerder opgestelde journaalregels bevatten daarover het volgende:

"gesprek met moeder: moeder vertelt op chaotische manier de relatie met vader van E; ze hebben jaren een LAT-relatie gehad; in deze relatie is E geboren. Vader heeft op een gegeven moment een andere relatie gekregen; is op een gegeven moment met deze vrouw gaan samenwonen. Moeder wist hier jaren niets van af, ondanks E hier diverse malen over vertelde aan moeder; moeder wuifelde deze informatie weg. Op school is er de afgelopen jaren ook veel misgegaan. Dit was de reden om 2 mnd geleden een nieuwe school voor $\mathrm{E}$ te zoeken. Op deze school heeft E 2 wn geleden blijkbaar verteld over vermeend sexueel misbruik (betast door neef vader?); pt is hierna door de Raad van Kinderbescherming weggehaald. Overmorgen is er een hoorzitting. Enkele mnd geleden is de moe- 
der van E erachter gekomen dat vader een andere vrouw heeft; ze heeft vader gevolg, en ging toen stiekem naar binnen, en confronteerde hem, hierbij heeft vader haar hardhandig vastgepakt bij de armen, en wilde haar op gezicht slaan. Ook pakte hij een kapmes, en dreigde haar hiermee. Ze is kunnen vluchten. Politie is erbij geroepen, en heeft vader geboeid. Sinds dit incident is het contact tussen vader en moeder verminderd. Moeder laatte nog wel toe dat vader E naar school bracht en weer naar huis. E heeft tegen moeder in het verleden mogelijk wel iets verteld over sexueel misbruik, maar moeder lijkt in haar verhaal aan te geven hier niet iets serieus mee te hebben gedaan."

2.6 Vervolgens heeft verweerder op dezelfde dag een gesprek gehad met de vader. Daarvan heeft verweerder het volgende opgetekend:

"gesprek met vader: E 2 wkn weggehaald geleden door de Raad van Kinderbescherming. Er werd gezegd dat E wordt geslagen bij moeder thuis (school heeft dit gemeld); ze is toen door 4 agenten meegenomen, over 2 dgn hoorzitting. Vader wil medische verklaring. E woont bij moeder thuis; vader zegt vrijwel dagelijks bij haar/haar moeder thuis te zijn; vader zegt dat hij E helpt haar met huiswerk ed; hij blijft soms ook overnachten bij E en haar moeder. Tot 1 jr geleden heeft E ged 6 jr bij vader gewoond, samen met de moeder van E. Vader heeft 2 vrouwen. Vader heeft 6 mnd geleden ruzie gekregen met moeder van E, toen bleek dat andere partner van vader zwanger was. Er is toen Politie bijgekomen ivm verbaal geweld (geen fysiek geweld vlg pt); daarna ging het vlg vader prima. Totdat $\mathrm{E}$ werd weggehaald, was het contact met pt en moeder van E goed. Onduidelijk wie een melding heeft gedaan. Vader heeft E nooit erkend; vader wil dit door deze gebeurtenis nu wel gaan doen."

2.7 Bij brief van 25 april 2016 heeft de RvdK aan de moeder verzocht toestemming te geven voor het benaderen van personen die beroepsmatig bij het gezin betrokken zijn en voor het verstrekken van informatie door deze informanten. Bij die brief was een "Machtiging opvragen informatie" gevoegd waarop was vermeld:

$$
\begin{aligned}
& \text { “Persoonsgegevens } \\
& \text { Uw naam [naam van de moeder] } \\
& \text { Naam minderjarige } \\
& -\quad \text { [volledige namen E] } \\
& \text { Informanten } \\
& -\quad \text { Melder, CJG } \\
& -\quad \text { F } \\
& -\quad \text { School E } \\
& -\quad \text { Huisarts } \\
& -\quad \text { Politie } \\
& -\quad \text { Gezinsvoogd } \\
& -\quad \text { G } \\
& -\quad \text { Ouderschap blijft } \\
& -\quad \text { Ambulante spoedhulp } \\
& -\quad \text { Ziekenhuis } \\
& -\quad \text { Pleegouders } \\
& \text { Ondertekening ouder } \\
& \text { Handtekening voor akkoord } \\
& \text { (...)” }
\end{aligned}
$$

De moeder heeft dit machtigingsformulier ondertekend en daarop F doorgestreept en vervangen door $\mathrm{H}$ en bij "huisarts", toegevoegd: [naam verweerder].

2.8 Op 13 mei 2016 heeft een medewerker van de RvdK verweerder gebeld en aangegeven dat de Raad bezig was met een onderzoek naar E, waarbij onderzocht werd of een verlenging van de OTS noodzakelijk was. Daarbij is aangegeven dat er schriftelijke toestemming was verkregen van de moeder om verweerder te benaderen voor het verkrijgen van informatie en dat de RvdK meerdere vergeefse pogingen had gedaan om de vader te bereiken.

2.9 Bij e-mail van 17 mei 2016 heeft de medewerker van de RvdK de inhoud van het onder 2.8 genoemde telefoongesprek bevestigd door middel van een daarvan opgemaakt verslag. Dit verslag bevat onder meer het volgende:

“Zorgen 
E komt iets meer dan gemiddeld bij de huisarts. De laatste tijd is E met de klachten acute buikpijn en een abces bij de huisarts geweest. De huisarts is nog niet op de hoogte van de operatie van E en hoe dat is verlopen. In april 2015 is E bij de huisarts geweest, vanwege een bloedneus en een knik in haar neus, omdat zij haar neus had gestoten. In november 2013 is E bij de huisarts geweest, vanwege een kneuzing in haar ellenboog. De verklaring was dat zij op school van de trap was gevallen. In 2013 is daarnaast sprake geweest van buikklachten. Wat langer geleden heeft $\mathrm{E}$ last gehad van hoest- en keelklachten en is haar voet in 2009 tussen de spaken van een fiets gekomen. E is nooit bij de huisarts geweest in verband met psychische klachten.

De huisarts is op de hoogte van de problemen tussen de ouders en meldingen die zijn gedaan bij het Advies- en Meldpunt Kindermishandeling, waaronder een melding van huiselijk geweld in 2014. Er is sprake geweest van een LAT-relatie tussen de ouders. Het verhaal van de vader is daarover anders dan dat van de moeder. (...)

Bij beide ouders is sprake van psychische problematiek. De vader is gediagnosticeerd met schizofrenie en krijgt daarvoor behandeling. De moeder zou ook behandeling krijgen voor psychische problematiek, waarvoor dat is weet de huisarts niet, omdat de moeder een andere huisarts heeft.

(...)

Sterke punten

De huisarts heeft nooit lichamelijk letsel geconstateerd bij E wat zou kunnen wijzen op lichamelijke mishandeling of op seksueel misbruik. (...)"

\section{De klacht}

Klagers verwijten verweerder dat hij informatie over E, de vader en de moeder aan de RvdK heeft verstrekt.

\section{Het standpunt van verweerder}

Verweerder heeft de klacht en de daaraan ten grondslag gelegde stellingen bestreden. Voor zover nodig wordt daarop hieronder ingegaan.

\section{De beoordeling}

5.1 Bij de beoordeling van de klacht stelt het College het volgende voorop.

5.2 Op grond van art. 1:240 BW kan een persoon die een beroepsgeheim heeft zonder toestemming van degene die het betreft aan de RvdK inlichtingen verstrekken, indien dit noodzakelijk kan worden geacht voor de uitoefening van de taken van de RvdK. Deze bepaling is (toen nog als art. 1:243 lid 2 BW) ingevoerd bij de Wet van 26 september 2002, Stb. 515 tot wijziging van de Wet op de jeugdhulpverlening (verder: Wjhv) in verband met de adviesen meldpunten kindermishandeling. Bij die wet werd een soortgelijke bepaling opgenomen (in art. $34 \mathrm{c}$ lid $3 \mathrm{Wjhv}$ ) voor het verstrekken van inlichtingen aan een advies- en meldpunt kindermishandeling, zij het dat art. 34c lid $3 \mathrm{Wjhv}$ de mogelijkheid van doorbreking van de geheimhoudingsplicht beperkte tot het geval waarin dit noodzakelijk kan worden geacht om een situatie van kindermishandeling te beëindigen of een redelijk vermoeden van kindermishandeling te onderzoeken. Gelet op de vergelijkbaarheid van de taken van de $\mathrm{RvdK}$ en de AMK's werd het wenselijk geacht voor beide instanties een gelijksoortige uitzondering op de geheimhoudingsplicht in te voeren. De Memorie van Toelichting op art. 34c lid $3 \mathrm{Wjhv}$ vermeldde (Tweede Kamer, vergaderjaar 2000-2001, 27842, nr. 3):

"Met deze bepaling wordt op zich geen nieuwe mogelijkheid gecreëerd om het beroepsgeheim te doorbreken, maar wordt de bestaande mogelijkheid om in geval van conflict van plichten het beroepsgeheim te kunnen doorbreken gecodificeerd. (...)

Het zoeken naar een antwoord op de vraag of in een concreet geval het beroepsgeheim kan/ moet worden doorbroken, blijft echter de eigen 
beroepsverantwoordelijkheid van de hulpverlener. Van belang hierbij is en blijft wel of bij de beslissing het beroepsgeheim al dan niet te doorbreken, zorgvuldig is gehandeld. Hiervoor zijn in de literatuur en jurisprudentie zorgvuldigheidseisen ontwikkeld. De KNMG heeft op grond hiervan bepaalde richtlijnen opgesteld teneinde een zorgvuldige afweging van belangen in geval van conflict van plichten te verzekeren. Deze worden met het voorgestelde derde lid van artikel $34 \mathrm{c}$ niet overbodig. Wij ondersteunen de ontwikkeling van protocollen, voor de verschillende beroepsgroepen, zoals die van de KNMG, omdat deze naast de voorgestelde wettelijke bepaling nog meer zekerheid kunnen bieden dat een afweging bij een conflict van plichten zorgvuldig zal zijn gemaakt."

Uit deze passage in de Memorie van Toelichting volgt dat de wetgever met de invoering van de bepaling geen wijziging van de bestaande situatie heeft beoogd, maar (slechts) een codificatie. Aangenomen moet worden, gelet op de gelijke strekking van beide bepalingen, dat dit evenzeer geldt voor de invoering van (destijds art. 1:243 lid 2, thans) art 1:240 BW. Dit betekent dat een doorbreking van het beroepsgeheim op verzoek van de RvdK op de voet van artikel 1:240 BW niet anders dient te worden beoordeeld dan een "spontane" doorbreking van het beroepsgeheim.

5.3 Het College is van oordeel dat verweerder terecht heeft aangenomen dat hij de patiëntgegevens met betrekking tot $\mathrm{E}$ mocht delen met de Raad voor de Kinderbescherming. Gelet op de door de moeder, die belast was met het gezag over E, ondertekende machtiging, mocht verweerder redelijkerwijs ervan uitgaan dat de moeder hem als wettelijke vertegenwoordigster van E toestemming gaf voor doorbreking van zijn beroepsgeheim ten aanzien van zijn patiënte E. Dat de moeder, zoals zij ter zitting heeft verklaard, niet begreep dat zij hiervoor tekende, omdat zij dacht dat het alleen ging om informatie ten behoeve van een ingreep die E moest ondergaan, kan verweerder niet worden aangerekend. De tekst van de machtiging is ruim en alge- meen en niet gebleken is dat verweerder meer informatie over E heeft verstrekt dan waarvan hij redelijkerwijs kon menen dat deze relevant zou kunnen zijn en dat daarvoor toestemming was gegeven. In zoverre is de klacht niet gegrond.

5.4 Dat ligt anders wat betreft de gegevens die verweerder van de moeder had vernomen in het gesprek op 29 maart 2016. De door de moeder ondertekende machtiging zag, gelet op de tekst daarvan, uitsluitend op patiëntgegevens met betrekking tot E. Uit de inhoud van het besprokene zoals genoteerd door verweerder blijkt niet dat dat over problemen van/met E ging, maar veeleer over een probleem van de moeder zelf. Niet is gebleken dat de moeder in dat gesprek enig verband had gelegd tussen enerzijds het door de moeder in dat gesprek gemelde incident van het zwaaien met een hakbijl door de vader, hetgeen zich zou hebben afgespeeld tijdens een ruzie tussen de moeder en de vader ten huize van de vader, waar E niet woonde en zonder dat E daarbij aanwezig was, terwijl de vader geen ouderlijk gezag had over E, en anderzijds het welzijn van E. De moeder heeft ter zitting verklaard dat zij aan het begin van het gesprek met verweerder heeft gezegd dat wat zij hem vertelde vertrouwelijk was en geheim moest blijven. Verweerder heeft dit niet weersproken. Gelet op deze gang van zaken mocht verweerder op grond van de door de moeder ondertekende machtiging niet zonder meer aannemen dat hij daarmee ook was ontslagen uit de verplichting tot geheimhouding van het op 29 maart 2016 besprokene. Weliswaar was de moeder geen (vaste) patiënte van verweerder, maar het College is van oordeel dat het beroepsgeheim van verweerder zich in de gegeven omstandigheden uitstrekte tot hetgeen de moeder in dat gesprek onder uitdrukkelijk beding van vertrouwelijkheid aan hem had verteld.

5.5 Ook wat betreft de gegevens die verweerder over de vader heeft verstrekt aan de RvdK kan niet worden gezegd dat hij toestemming had om zijn beroepsgeheim te doorbreken. De toestemming van de moeder in het machtigingsformulier zag op gegevens met betrekking tot $\mathrm{E}$ en niet op arts-patient gegevens met betrekking tot de vader. De moeder was ook niet in de positie om verweerder te ont- 
slaan uit zijn geheimhoudingsplicht ten aanzien van een andere patiënt dan E (in dit geval: de vader). Verweerder had derhalve geen toestemming om medische gegevens van de vader aan derden te verstrekken.

5.6 Ook zonder toestemming kan onder omstandigheden een doorbreking van het beroepsgeheim geoorloofd, en soms zelfs verplicht, zijn. Het gaat dan, toegespitst op deze zaak, om situaties waarin sprake is van een botsing tussen enerzijds de geheimhoudingsplicht van de arts en anderzijds diens plicht om (ernstige vermoedens van) kindermishandeling te melden bij dan wel relevante informatie daarover te delen met de daarvoor aangewezen instanties. Voor die gevallen heeft de KNMG de Meldcode Kindermishandeling en Huiselijk Geweld in het leven geroepen, die een stappenplan bevat dat de arts dient te volgen wanneer hij overweegt over te gaan tot doorbreking van zijn beroepsgeheim. Dit stappenplan vormt de praktische neerslag van de bij doorbreking van het beroepsgeheim te betrachten proportionaliteit en subsidiariteit: doorbreking is slechts op zijn plaats indien geen andere middelen (meer) voorhanden zijn om het gewenste doel te bereiken, en slechts voor zover de doorbreking voor dat doel noodzakelijk is. De te volgen stappen zijn:

1 aanwijzingen en gegevens verzamelen en vastleggen in het medisch dossier;

2 collegiaal overleg en advies vragen aan Veilig Thuis;

3 aanwijzingen en signalen van kindermishandeling bespreken met de ouders en/of het kind, tenzij dit niet mogelijk is uit vrees voor de veiligheid of gezondheid van het kind, als redelijkerwijs gevreesd moet worden dat de arts het kind en/of de ouders daardoor uit het oog zal verliezen of als de arts vreest voor zijn eigen veiligheid;

4 eventueel overleggen met andere bij het gezin betrokken hulpverleners of beroepskrachten;

5 hierin worden mogelijkheden van monitoring of melding uitgewerkt.

Bij stap 3 tekent het College nog aan dat de arts in beginsel moet trachten toestemming te verkrijgen van de patiënt voor doorbreking van het beroepsgeheim.

5.7 Het College is van oordeel dat verweerder in dit geval na afweging van de betrokken belangen in redelijkheid niet op deze wijze tot de verstrekking van gegevens betreffende het gesprek op 29 maart 2016 aan de RvdK had mogen overgaan. Hetzelfde geldt voor het verstrekken van patiëntgegevens van de vader. Hiermee heeft verweerder in de gegeven omstandigheden een disproportionele inbreuk gemaakt op de persoonlijke levenssfeer van klagers. Het College motiveert dit oordeel als volgt.

5.8 Klager beschikte ten tijde van de verstrekking van de informatie niet zelf over concrete aanwijzingen dat sprake was van kindermishandeling (stap 1). Weliswaar kwam E volgens verweerder vaker dan gemiddeld op consult, maar dit had hem tot dan toe geen aanleiding gegeven dat gegeven met E, haar moeder of haar vader te bespreken (stap 3) noch om dit met een collega-huisarts te bespreken, laat staan dit aan derde-instanties te melden (stap 2). Integendeel, verweerder heeft desgevraagd aan AMK geantwoord dat hij geen zorgen had omtrent $\mathrm{E}$ (zie hiervoor onder 2.3).

5.9 De aanleiding voor het onderzoek van de RvdK vormde kennelijk een signaal van sexueel misbruik door een familielid (niet zijnde de moeder of de vader). Ook dit gegeven vormde naar het oordeel van het College onvoldoende grond om met voorbijgaan aan klagers de betreffende gegevens aan de RvdK te verstrekken.

5.10 Het relaas van de moeder op 29 maart 2016 (zie hiervoor onder 2.5), dat diezelfde dag was weersproken door de vader (zie hiervoor onder 2.6), vormde daartoe evenmin voldoende grond. In elk geval gaf deze van de moeder verkregen informatie geen grond om af te wijken van het te volgen stappenplan bij het doorbreken van het beroepsgeheim in verband met kindermishandeling en de daarbij geldende eisen van proportionaliteit en subsidiariteit. Verweerder had, indien hetgeen de moeder hem had verteld hem zozeer verontrustte dat hij dit met derden wilde delen, eerst contact moeten leggen met de moeder om dit met haar te bespreken en te trachten haar toestemming voor doorbreking van het 
geheim te verkrijgen. Datzelfde geldt voor de doorbreking van het beroepsgeheim ten aanzien van de patiëntgegevens van de vader. Dat de medewerker van de RvdK verweerder meedeelde dat diverse pogingen om contact te leggen met de vader waren mislukt, ontsloeg verweerder niet van de verplichting om contact op te nemen met de vader, die al jarenlang als patiënt bij hem kwam.

5.11 Het College acht de klacht dus in deze opzichten gegrond. Het College ziet aanleiding af te zien van het opleggen van een maatregel, nu het College er niet aan twijfelt dat verweerder heeft gehandeld met goede intenties en de geldende wet- en regelgeving de beroepsbeoefenaar weinig duidelijkheid biedt over het te hanteren beoordelingskader wanneer hem door een instantie als de RvdK om informatie betreffende een patiënt wordt gevraagd op grond van artikel 1:240 BW, terwijl daarover in de literatuur verschillende zienswijzen bestaan.

5.12 De conclusie is dat verweerster in strijd heeft gehandeld met de zorg die hij ten opzichte van klagers behoorde te betrachten zoals bedoeld in artikel 47 , eerste lid, van de Wet op de beroepen in de individuele gezondheidszorg. De klacht is dan ook gedeeltelijk gegrond. Hoewel de klacht gegrond is, zal het College verweerder geen maatregel opleggen, om de onder 5.11 vermelde redenen.

$5.13 \mathrm{Om}$ redenen aan het algemeen belang ontleend zal deze beslissing, zodra zij onherroepelijk is, op de voet van artikel 71 van de Wet op de beroepen in de individuele gezondheidszorg bekend worden gemaakt op hierna te vermelden wijze.

\section{De beslissing}

Het Regionaal Tuchtcollege voor de Gezondheidszorg te Den Haag beslist als volgt:

verklaart de klacht gegrond, zonder oplegging van een maatregel.

bepaalt dat deze beslissing, zodra zij onherroepelijk is, in de Nederlandse Staatscourant zal worden bekendgemaakt en aan het tijdschrift Medisch Contact ter bekendmaking zal worden aangeboden.

\section{Noot}

1. De aangeklaagde huisarts in bovenstaande zaak heeft op verzoek van de Raad voor de Kinderbescherming informatie verstrekt over $\mathrm{E}$ en haar beide ouders. De vader en E zijn patiënt bij de huisarts, maar de moeder heeft een andere huisarts. De Raad voor de Kinderbescherming voerde een onderzoek uit naar de vraag of, als vervolg op een spoedmaatregel (voorlopige ondertoezichtstelling) die door de rechter was uitgesproken in verband met een vermoeden van kindermishandeling, voor $\mathrm{E}$ - een meisje van bijna twaalf jaar - een maatregel van ondertoezichtstelling noodzakelijk was. De moeder, die alleen het gezag over $\mathrm{E}$ heeft, heeft een machtigingsformulier ondertekend waarin zij de Raad voor de Kinderbescherming toestemming gaf om onder meer de huisarts van $\mathrm{E}$ te benaderen voor het verkrijgen van informatie over E. De huisarts verstrekte vervolgens zowel informatie over E als over de vader en moeder van $\mathrm{E}$ aan de Raad voor de Kinderbescherming en doorbrak daarmee het medisch beroepsgeheim. De centrale vraag in deze zaak is of dit gerechtvaardigd was of niet; hieronder gaan wij daar nader op in.

2. Het verstrekken van informatie door de huisarts is gebaseerd op art. 1:240 BW. In deze bepaling is geregeld dat een persoon met een beroepsgeheim zonder toestemming van degene die het betreft aan de Raad voor de Kinderbescherming inlichtingen kan verstrekken als dit noodzakelijk kan worden geacht voor de uitoefening van de taken van de Raad. Met deze in 2004 wettelijk ingevoerde bepaling, die samen met een soortgelijke bepaling voor melden zonder toestemming bij het Advies- en Meldpunt Kindermishandeling (nu: Veilig Thuis) werd geïntroduceerd, werd de mogelijkheid tot gegevensverstrekking bij zorgen over een kind zonder toestemming van de direct betrokkenen, gecodificeerd. De gegevensverstrekker zal derhalve bij een verzoek tot gegevensverstrekking van de Raad voor de Kinderbescherming steeds zorgvuldig moeten beslissen tot een doorbreking van het medisch beroepsgeheim zonder toestemming. De KNMG-meldcode Kinder- 
mishandeling en huiselijk geweld (2015) helpt artsen bij het nemen van de beslissing om al dan niet gegevens te verstrekken. Voor beslissingen over het op eigen initiatief melden bij vermoedens van kindermishandeling zonder toestemming van direct betrokkenen (aan Veilig Thuis) is in art. 4 KNMGmeldcode een stappenplan opgenomen.

3. Voor het verstrekken van informatie op verzoek van de Raad voor de Kinderbescherming geldt evenwel geen stappenplan, maar is art. 10 KNMG-meldcode van toepassing. In lid 3 van dit artikel is bepaald dat de arts die door de Raad voor de Kinderbescherming wordt benaderd met een verzoek om informatie, deze informatie verstrekt indien dit noodzakelijk is om kindermishandeling te stoppen of een redelijk vermoeden daarvan te laten onderzoeken. De achterliggende gedachte bij het verstrekken van informatie op verzoek is dat de arts minder afwegingsruimte behoeft dan in geval hij zelf meldt, omdat als informatie wordt gevraagd in het kader van een lopend onderzoek, een redelijk vermoeden en dus de noodzaak voor het onderzoeken van mogelijke kindermishandeling een gegeven is. Uiteraard verdient het de voorkeur dat de arts informatie verstrekt mét toestemming van de ouders met gezag, en daar waar het informatie over (een van beide) ouders betreft mét de toestemming van de desbetreffende ouder(s). De kracht van de KNMGmeldcode is er nu juist in gelegen dat áls toestemming van betrokkene(n) voor het doorbreken van het medisch beroepsgeheim ontbreekt, de arts niet in een verlammende patstelling geraakt, maar in het belang van het kind informatie kan verstrekken. De opstellers van de KNMG-meldcode zijn directief in hun formulering: de arts verstrekt informatie om kindermishandeling te stoppen of een redelijk vermoeden daarvan te laten onderzoeken. Daarvoor is niet vereist dat de arts zelf ook al een vermoeden van kindermishandeling heeft. Het is dus van belang dat de vragende instantie de arts goed informeert dat informatie wordt gevraagd in het kader van zorgen over mogelijke kindermishandeling.

4. In de onderhavige zaak verzocht de Raad voor de Kinderbescherming de huisarts om informatie over
E en haar ouders. Het tuchtcollege sauveert de doorbreking van het medisch beroepsgeheim door de arts voor zover het gaat om het verstrekken van informatie over E aan de Raad voor de Kinderbescherming, omdat daarvoor toestemming is gegeven door de gezagdragende moeder (zie onder 5.3). Opmerkelijk is wel dat de moeder ervan uitging dat zij toestemming gaf voor haar dochter voor het ondergaan van een medische ingreep. Hier blijkt maar weer eens uit hoe belangrijk het is dat de Raad voor de Kinderbescherming ook duidelijk uitlegt aan de gezagdragende ouder(s) waarvoor informatie wordt ingewonnen, zodat toestemming voor het eventueel doorbreken van het medisch beroepsgeheim door de (huis)arts gericht kan worden gegeven. Anders wordt het al snel het probleem van de (huis)arts. Het tuchtcollege rekent het de huisarts in deze zaak echter niet aan dat hij heeft aangenomen dat de moeder met gezag toestemming had gegeven voor gegevensverstrekking over E. Daarbij oordeelt het tuchtcollege dat de huisarts ook zorgvuldig heeft gehandeld door niet meer gegevens te verstrekken dan de volgens hem relevante gegevens over E. Bij informatieverstrekking blijft immers altijd voorop staan dat niet meer gegevens worden verstrekt dan die strikt noodzakelijk zijn.

5. Voor de beoordeling van het doorbreken van het medisch beroepsgeheim voor zover het informatie over de vader en de moeder betreft, springt in deze zaak in het oog dat het Regionaal Tuchtcollege voor de Gezondheidszorg te Den Haag een nieuwe toetsingsmaatstaf aanlegt voor gegevensverstrekking op verzoek. Het tuchtcollege toetst immers de doorbreking van het medisch beroepsgeheim in de situatie waarin de arts wordt bevraagd niet aan art. 10 KNMG-meldcode, maar aan het stappenplan dat in art. 4 KNMG-meldcode is neergelegd voor het doen van een melding uit eigen beweging (in de woorden van het tuchtcollege: 'spontane melding') aan Veilig Thuis. Dat stappenplan uit art. 4 KNMG-meldcode is niet bedoeld voor het doen van een spontane melding aan de Raad voor de Kinderbescherming, laat staan voor het op verzoek verstrekken van informatie aan de Raad voor de Kinderbescherming. Het stap- 
penplan is bedoeld voor het doen van een melding uit eigen beweging naar aanleiding van vermoedens van kindermishandeling aan Veilig Thuis en geeft zo (ten dele) handen en voeten aan art. 5.2.6. WMO Hetzelfde geldt voor het Basismodel meldcode huiselijk geweld en kindermishandeling. ${ }^{1}$ Dit is een door het Ministerie van VWS opgestelde code voor functionarissen die binnen een instelling, organisatie of praktijk een meldcode opstellen - een verplichting op grond van de Wet verplichte meldcode huiselijk geweld en kindermishandeling. ${ }^{2}$

6. Onder 5.2 overweegt het tuchtcollege dat - gelet op de vergelijkbare taken van de Raad voor de Kinderbescherming en de AMK's (bedoeld wordt AMHK's/Veilig Thuis) - er twee gelijksoortige uitzonderingen op de geheimhoudingsplicht zijn ingevoerd. Het college doelt hiermee zonder meer op de meldrechten zoals die thans zijn neergelegd in art 1:240 BW (voor verstrekken van informatie aan de Raad voor de Kinderbescherming) en art. 5.2.6 WMO (voor verstrekken van informatie aan Veilig Thuis). Beide meldrechten geven de arts de bevoegdheid het medisch beroepsgeheim te doorbreken zonder daarvoor toestemming te hebben van betrokkenen en gelden, althans volgens de wetgever, in de context van conflict van plichten. ${ }^{3}$ In dat conflict van plichten-kader geldt een toetsingskader dat uitgaat van 'zwijgen-tenzij' en dat de volgende criteria kent: (1) alles is in het werk gesteld om toestemming tot doorbreking van het geheim te krijgen; (2) het niet doorbreken van het geheim levert voor een ander/de patiënt ernstige schade op; (3) er is sprake van gewetensnood bij de arts door het handhaven van de zwijgplicht; (4) er is geen andere weg dan doorbreking van het geheim om het pro-

1 Basismodel meldcode huiselijk geweld en kindermishandeling. Stappenplan voor het handelen bij signalen van huiselijk geweld en kindermishandeling, Den Haag: Ministerie van Volksgezondheid, Welzijn en Sport 2016.

2 Wet verplichte meldcode huiselijk geweld en kindermishandeling, Stb. 2013, 142. Deze verplichting is inmiddels ook opgenomen in art. 8 Wet kwaliteit klachten en geschillen zorg.

3 Kamerstukken II 2000/01, 27842, 3, p. 24-25 en p. 35 (MvT). bleem op te lossen; (5) het moet vrijwel zeker zijn dat door doorbreking van het geheim de schade aan de ander/de patiënt kan worden voorkomen of beperkt; (6) het geheim wordt zo min mogelijk geschonden. Aan die criteria toetst het tuchtcollege in bovenstaande zaak niet, maar wél aan het stappenplan zoals vermeld in art. 4 KNMG-meldcode. Dat stappenplan kent een ander uitgangspunt dan het conflict van plichten-toetsingskader. Het accent ligt in het stappenplan immers op spreken, terwijl het conflict van plichten-toetsingskader uitgaat van 'zwijgen-tenzij'. ${ }^{4}$ Met het stappenplan is de ruimte om te melden zonder toestemming bij vermoedens van kindermishandeling voor artsen die daarmee hun medisch beroepsgeheim doorbreken, veel groter.

7. In de KNMG-meldcode wordt een duidelijk onderscheid gemaakt tussen beide situaties: een melding op eigen initiatief aan de Raad voor de Kinderbescherming (art. 10 lid 1 KNMG-meldcode) en op verzoek van de Raad voor de Kinderbescherming (art. 10 lid 3 KNMG-meldcode). Een dergelijk onderscheid geldt op grond van de KNMG-meldcode ook voor de situatie waarin de arts gegevens verstrekt aan Veilig Thuis: art. 4 KNMG-meldcode geldt voor een spontane melding met daarbij een stappenplan en art. 6 KNMG-meldcode geldt voor het op verzoek van Veilig Thuis verstrekken van informatie zonder toestemming van de direct betrokkenen. Het is opvallend dat het tuchtcollege noemt dat 'de geldende wet- en regelgeving de beroepsbeoefenaar weinig duidelijkheid biedt over het te hanteren beoordelingskader wanneer hem door een instantie als de Raad voor de Kinderbescherming om informatie over een patiënt wordt gevraagd op grond van art. 1:240 BW', aangezien het tuchtcollege de KNMG-meldcode op dit punt zelf onjuist heeft toegepast. Dat neemt niet weg dat ook de KNMG-meldcode op dit punt niet uitblinkt in duidelijkheid. Het is dan ook alleszins te verwachten dat voor artsen die met situaties te maken krijgen waarin zij door

4 C.A. Bol \& J.C.J. Dute, 'Melding van kindermishandeling: afscheid van conflict van plichten?', TvGR 2014, p. 14. 
Veilig Thuis of door de Raad voor de Kinderbescherming om informatie worden gevraagd, onduidelijk is welke factoren zij moeten meewegen bij hun beslissing over het verstrekken van informatie en over de vraag welke informatie zal worden verstrekt.

8. Een andere vraag is waarom in de KNMG-meldcode verschillende beoordelingscriteria worden gehanteerd: enerzijds een stappenplan voor het beslissen over gegevensverstrekking zonder toestemming op eigen initiatief aan Veilig Thuis en anderzijds, indien de Raad voor de Kinderbescherming om informatie verzoekt, het criterium dat de arts - bij voorkeur met toestemming van ouders en/ of kind - alle tot zijn beschikking staande informatie verstrekt die noodzakelijk is om kindermishandeling te stoppen of een redelijk vermoeden daarvan te laten onderzoeken. De arts informeert betrokkenen tevoren, tenzij dit niet mogelijk is in verband met de veiligheid van het kind en/of anderen, als redelijkerwijs gevreesd moet worden dat de arts het kind en/of de ouders uit het oog zal verliezen of als de arts vreest voor zijn eigen veiligheid.' Dit heeft wellicht te maken met het feit dat op basis van de Wet verplichte meldcode huiselijk geweld en kindermishandeling een stappenplan moest worden ingevoerd voor meldingen op eigen initiatief aan Veilig Thuis. Verwarrend is dan weer dat de achterliggende gedachte bij het verstrekken van informatie op verzoek weliswaar is dat de arts mínder afwegingsruimte wordt gelaten, maar tegelijkertijd de 'leer van conflict van plichten' in de KNMG-meldcode nog eens wordt bevestigd. ${ }^{5}$ Temeer omdat gegevensverstrekking op verzoek van de Raad voor de Kinderbescherming of Veilig Thuis zonder toestemming essentieel is bij vermoedens van kindermishandeling, zodat kinderen in nood beter beschermd kunnen worden. Verschillende beoordelingscriteria leiden, zoals in deze zaak ook duidelijk is, tot onduidelijkheid.

KNMG-Meldcode Kindermishandeling en huiselijk geweld, Utrecht: KNMG 2015, p. 45-46.
9. Ofschoon de tuchtrechter doorgaans wél aan de KNMG-meldcode toetst als het om een 'spontane melding' gaat, kan dit niet worden gezegd van gegevensverstrekking op verzoek. Tuchtrechters toetsen soms aan de KNMG-meldcode en soms aan het conflict van plichten, dat toch echt strengere eisen stelt aan het doorbreken van het medisch beroepsgeheim. ${ }^{6}$ Op grond van de KNMG-meldcode is immers niet de gedachte dat bij hoge uitzondering gegevens worden verstrekt aan de Raad voor de Kinderbescherming, maar dat dit geschiedt in geval van een onderzoek naar een vermoeden van kindermishandeling.

10. Indien het tuchtcollege de doorbreking van het medisch beroepsgeheim strikt zou hebben getoetst aan art. $10 \mathrm{KNMG-meldcode,} \mathrm{dan} \mathrm{zou} \mathrm{dit} \mathrm{hebben}$ geleid tot een afwijzing van de klacht, aangezien de arts die wordt benaderd door de Raad voor de Kinderbescherming op grond van de KNMG-meldcode álle tot zijn beschikking staande informatie die noodzakelijk is om kindermishandeling te stoppen of een redelijk vermoeden te laten onderzoeken dient te verstrekken. Het nog te nemen besluit over het al dan niet indienen van een verzoek tot een ondertoezichtstelling stond zonder meer in het licht van de zorgen die er waren over mogelijke kindermishandeling.

11. Bovenstaande uitspraak biedt artsen aldus iets minder ruimte om informatie op verzoek van de Raad voor de Kinderbescherming te verstrekken. De tuchtrechter past de KNMG-meldcode anders toe door het op verzoek verstrekken van informatie aan de Raad voor de Kinderbescherming te toetsen aan het stappenplan uit art. 4 KNMG-meldcode dat bedoeld is voor het doen van een spontane melding aan Veilig Thuis. Hierdoor valt er licht tussen de tuchtrechtelijke norm en de professionele norm. Daarnaast hinkt de code op twee gedachten door enerzijds met art. 10 lid 3 KNMG-meldcode te beogen dat de arts mínder afwegingsruimte wordt

6 Zie voor voorbeelden uit de jurisprudentie C.A. Bol \& J.C.J. Dute, 'Melding van kindermishandeling: afscheid van conflict van plichten?', TvGR 2014, p. 18. 
gegeven als de Raad voor de Kinderbescherming een onderzoek naar kindermishandeling heeft ingesteld en in dat kader om informatie vraagt en anderzijds de leer van het conflict van plichten nog eens te bevestigen. Dat komt de rechtszekerheid van de arts niet ten goede. De arts blijft immers blootstaan aan het risico door ouders tuchtrechtelijk te worden aangesproken. In bovenstaande uitspraak kan naar onze mening in ieder geval een oproep worden gelezen aan de beroepsgroep om een meer uniform toetsingskader aan te reiken voor de diverse situaties van gegevensverstrekking in geval van vermoedens van kindermishandeling.

Prof. mr. M.R. Bruning, hoogleraar Jeugdrecht aan de Faculteit der Rechtsgeleerdheid van de Universiteit Leiden Mr. drs. M.P. Sombroek, werkzaam bij de afdeling jeugdrecht en promovenda bij de afdeling privaatrecht van de Faculteit der Rechtsgeleerdheid van de Universiteit Leiden. 